\title{
A HABITAÇÃO POPULAR EM PRESIDENTE PRUDENTE - SP E O PLANEJAMENTO URBANO AMBIENTAL
}

\author{
Mayara Pissutti Albano, Alba Regina Azevedo Arana
}

Universidade do Oeste Paulista. E-mail: mayara albano@hotmail.com

\section{RESUMO}

A presente pesquisa objetivou estudar a inserção de habitação de interesse social, tendo como objeto de estudo, o Conjunto Habitacional Maré Mansa em Presidente Prudente -SP, visto que sua implantação, ocorrida sem um adequado planejamento urbano ambiental causou impactos ao meio ambiente. Situações como esta ocorrem, devido ao acelerado processo de urbanização, ocorrido nas ultimas décadas, que ocasionam cidades com infraestrutura deficitária de habitação digna e serviços públicos, e consequentemente, acentuam a segregação socioespacial. A ausência de políticas públicas de habitação e de execução de conjuntos habitacionais adequados, e a aprovação e a implantação de conjuntos sem a correta análise ambiental acarretam em cidades com acentuada expansão em áreas ilegais e reforçam a geração de espaços inadequados e/ou fortemente impactantes ao ambiente natural e construído. A metodologia foi baseada em levantamentos de campo, além de análises documentais de processos legal junto à Prefeitura Municipal, e judicial junto ao Ministério Público.

Palavras-chave: Habitação social, expansão urbana, planejamento ambiental.

\section{INTRODUÇÃO}

O processo de urbanização do Brasil, apresentou intensificação a partir da segunda metade do século $X X$, fato que pode ser compreendido através dos seguintes dados: a população residente nas urbes era de 18,8 milhões de habitantes contra 130 milhões no ano 2000. Os assentamentos humanos em pouco mais meio século, ampliaram-se de forma a abrigar mais de 125 milhões de pessoas, sendo 22 milhões delas apenas na última década do século passado (MARICATO, 2001).

Esse crescimento provocou uma acentuada expansão da malha voltada a áreas habitacionais, através de um gigantesco processo de construção de cidade legal e ilegal. Juntamente com a necessidade de moradia, surgem necessidades como saneamento básico, transportes, saúde, educação. Infelizmente, o crescimento urbano ocorreu de maneira inadequada. A inexistência de um planejamento prévio reforça a ocupação do território de forma não apropriada, improvisada ou não, as pessoas se adensam em assentamentos urbanos (MARICATO, 2001).

Essa situação vigente nos espaços urbanos brasileiros diminui a qualidade de vida, e acentua os problemas sociais e ambientais, causados principalmente por assentamentos ilegais. É através da avaliação das condições urbanas ambientais que se têm subsídios ao planejamento, 
visto que é uma maneira de reunir informações que venham cooperar para a qualidade de vida da população. O conceito de qualidade ambiental associa-se ao conceito de qualidade de vida, surgindo a necessidade de diagnóstico da existência ou não de condições mínimas de habitação e vivência, em termos sociais, ambientais, econômicos, entre outros.

Oliveira (1983 apud MACHADO, 1997) afirma que a qualidade ambiental está diretamente ligada à qualidade de vida, visto que vida e meio ambiente são intrínsecos. Ou seja, há uma interação e uma influência mútua entre ambos que varia na escala de tempo e lugar. Desta feita, pesquisas na área do planejamento urbano e ambiental, atentando à saúde e à qualidade de vida das populações, ratificam sua importância, especialmente quando relacionados aos resultados sociais, estéticos, educacionais, psicológicos e ecológicos.

O planejamento ambiental é fundamental para a constituição de espaços mais adequados aos seres humanos e menos impactante ao meio ambiente. A gestão ambiental do espaço urbano é de responsabilidade dos Poderes Públicos locais, e devem objetivar o desenvolvimento e o necessário equilíbrio entre a cidade e o meio ambiente (ARRUDA, 2001).

Há uma necessidade extrema de um planejamento urbano ambiental e de uma gestão adequada desse espaço, que olhe para as pessoas e para o meio ambiente natural e construído, a fim de mitigar os problemas existentes e antever o crescimento das cidades, para que ocorram de maneira planejada, controlada e com qualidade ambiental, para que a realidade possa ser diferente no futuro.

Esse trabalho objetiva verificar a ausência de Planejamento Urbano Ambiental, a falta de preocupação com os ambientes natural e construído, que reproduzem e reforçam o modelo de expansão urbana periférica e segregada ocorrido nas últimas décadas, que atingem principalmente a população de menor poder aquisitivo. Tendo como objeto de estudo, o Conjunto Habitacional Maré Mansa, executado em Presidente Prudente.

\section{O PLANEJAMENTO URBANO AMBIENTAL}

A Constituição Federal de 1988 afirma em seu capítulo sobre política urbana, que compete ao Poder Público Municipal realizar ações de controle e regulação sobre o planejamento, a gestão e o desenvolvimento urbanos.

Ferrari (1991), afirma que o planejamento urbano constitui um processo políticoadministrativo de governo que, embora deva estar apoiado em conhecimentos teóricos, precisa estar definido como políticas e diretrizes práticas; assim, verifica-se a relação do planejamento 
urbano com as políticas urbanas. O processo de planejamento urbano tem como objetivo, ordenar, articular e equipar o espaço, de modo racional, direcionando a malha urbana, suas áreas ou zonas, a determinados usos e funções (PHILIPPI Jr, ROMERO, BRUNA, 2004).

Os indicadores de qualidade de vida de uma determinada cidade, são reflexo da política pública, onde o Poder Público é o responsável por gerir os serviços, ratificando assim, a relação direta entre a eficácia da gestão pública e a qualidade de vida dos habitantes da cidade (DI SARNO, 2004). Uma boa qualidade de vida é um direito de todos, garantido pela CF de 1988, em seu artigo 225.

Dias (2005) afirma que há uma ligação direta com a qualidade de vida e proteção do meio ambiente, que constitui uma condição necessária para ocorrer o progresso social. Para Canepa (2007), a sustentabilidade está diretamente ligada à qualidade de vida, não só para o ser humano, mas para toda a biosfera, sem prejuízo do futuro, incluindo a sobrevivência da diversidade cultural e social humana, e biológica do planeta. E, buscando a sustentabilidade, o planejamento urbano é necessário, com revisão de seus conceitos, com inclusão real da questão ambiental. Urge, dessa forma, um planejamento considerado ambiental.

Assim, o Planejamento Urbano Ambiental, constitui-se numa junção do planejamento e análise ambiental, buscando o uso racional dos recursos naturais, de forma que seus limites e capacidade sejam respeitados, a fim de melhorar as condições de vida da população que reside nos espaços urbanos (MARIA, 2012). Por ser o habitat do homem, o ambiente urbano deve ser pensado e planejado de forma a garantir não apenas a sobrevivência, mas a vida da sociedade.

Contudo:

O mais "perfeito" plano em nada resolverá as questões ambientais, se o espaço não for entendido como uma instancia social e não como mero apoio das atividades humanas. O espaço físico é o reflexo não apenas dos processos naturais, como também das contradições da sociedade, na medida em que são os interesses socioeconômicos dos determinantes das formas de apropriação e exploração do espaço (ALMEIDA et al 1999, p 37).

Assim, conclui-se que o Planejamento Urbano Ambiental, na prática reconstrói o planejamento das cidades, promovendo uma reanálise do espaço urbano, das relações que envolvem a sociedade e natureza e, concomitantemente, persiste na busca de velhos ideais, que apesar de consensuais, ainda não foram efetivamente implantados, tais como: a importância do planejamento, o planejamento participativo e a própria questão ambiental. Sempre destacando a generalização de alguns aspectos e levando em conta o contexto em que cada cidade se insere. 


\section{CONJUNTO HABITACIONAL MARÉ MANSA - UM ESTUDO SOBRE OS PROBLEMAS} DECORRENTES DA AUSÊNCIA DE UM PLANEJAMENTO URBANO AMBIENTAL EM PRESIDENTE PRUDENTE - SP

Presidente Prudente é uma cidade média do interior paulista, possui uma população de aproximadamente 200.000 habitantes. Situa-se na região oeste do estado de São Paulo, próxima à divisa dos estados do Paraná e Mato Grosso do Sul. Sua colonização foi apoiada na implantação da estrada de ferro Sorocabana, com a estação ferroviária inaugurada em 1919. A partir de então sua estrutura urbana começou a se formar através da abertura dos dois primeiros loteamentos adjacentes à estação: a Vila Goulart e a Vila Marcondes, que receberam o nome dos dois colonizadores. A futura fusão das propriedades em 1921 deu origem à cidade (HONDA, 2000).

As quatro primeiras décadas após sua fundação foram marcadas por uma notória expansão territorial urbana, no entanto, sem planejamento e regulamentação legal, fato que influenciou diretamente a produção da cidade, provocando intensiva expansão da malha urbana. Durante as décadas de 1950 e 1960, o crescimento espacial foi reduzido, comparado às décadas anteriores (HONDA, 2011).

Em 1968 foi implantado o primeiro conjunto habitacional de Presidente Prudente através da Poupança Continental, financiado pelo Banco Nacional de Habitação (BNH). Desde então mais de trinta conjuntos habitacionais forma construídos da cidade de Presidente Prudente, seja com financiamento do Governo Federal, do Governo Estadual, da iniciativa privada, ou através de parcerias, totalizando 10.946 unidades entregues entre os anos de 1968 e 2009 (HONDA, 2011). Além desse total, a Prefeitura Municipal de Presidente Prudente, durante os anos de 1993 a 1996, concedeu direito de uso de 4.013 lotes urbanizados, em seis loteamentos.

Ao analisar o histórico da habitação social em Presidente Prudente, nota-se a ausência de um planejamento Urbano Ambiental, que regulamente a implantação dos conjuntos habitacionais, visto que na maioria se encontram nas áreas norte e oeste, na franja da malha urbana, caracterizando segregação socioespacial e reforçando a expansão periférica da cidade. Em outros casos já levantados por diversos autores, constata-se que há implantações de conjuntos habitacionais fortemente impactantes, como por exemplo, a falta de preocupação com área de mananciais, como também ocorreu na implantação do conjunto habitacional Maré Mansa, objeto de estudo esta pesquisa.

O conjunto habitacional Maré Mansa foi implantado na cidade de Presidente Prudente, através de uma empresa privada entre os anos de 1999 e 2001. O conjunto habitacional se 
encontra em área de mananciais, entre os córregos da Bomba e da Malandra, afluentes do córrego do Limoeiro, que por sua vez é afluente do rio Santo Anastácio, que pertence a bacia hidrográfica do Pontal do Paranapanema (BOIN, 1999).

O empreendimento está localizado aproximadamente à $8 \mathrm{~km}$ do centro da cidade, configurando uma caso de segregação socioespacial (Figura 1). Bonates (2008), afirma existir uma tendência de implantação dos conjuntos habitacionais no Brasil após a instituição da política implantada pelo regime militar através do $\mathrm{BNH}$, onde há uma forte tendência à periferização das cidades brasileiras, onde as moradias das classes mais baixas foram deslocadas para as franjas da malha urbana. Esta tendência pode ser observada também na cidade de Presidente Prudente, em especial no referido conjunto.

O empreendimento em questão, quando no Inácio de seu processo projetual, em fevereiro de 1999, possuía inúmeros pontos prejudiciais ao meio ambiente, que resultou um Termo de Compromisso de Ajustamento de Conduta firmado e assinado entre a Promotoria de Justiça do Meio Ambiente e de Habitação e Urbanismo de Presidente Prudente e a construtora responsável pela execução do Conjunto Habitacional Maré Mansa. Segundo esse documento, os compromissados se comprometeram a observar a legislação ambiental e também implantar uma série de compensações ambientais a fim de reparar os danos causados pela implantação do empreendimento. A execução foi acompanhada por um perito que fez levantamento à respeito dos impactos ambientais e possíveis ações para mitiga-los.
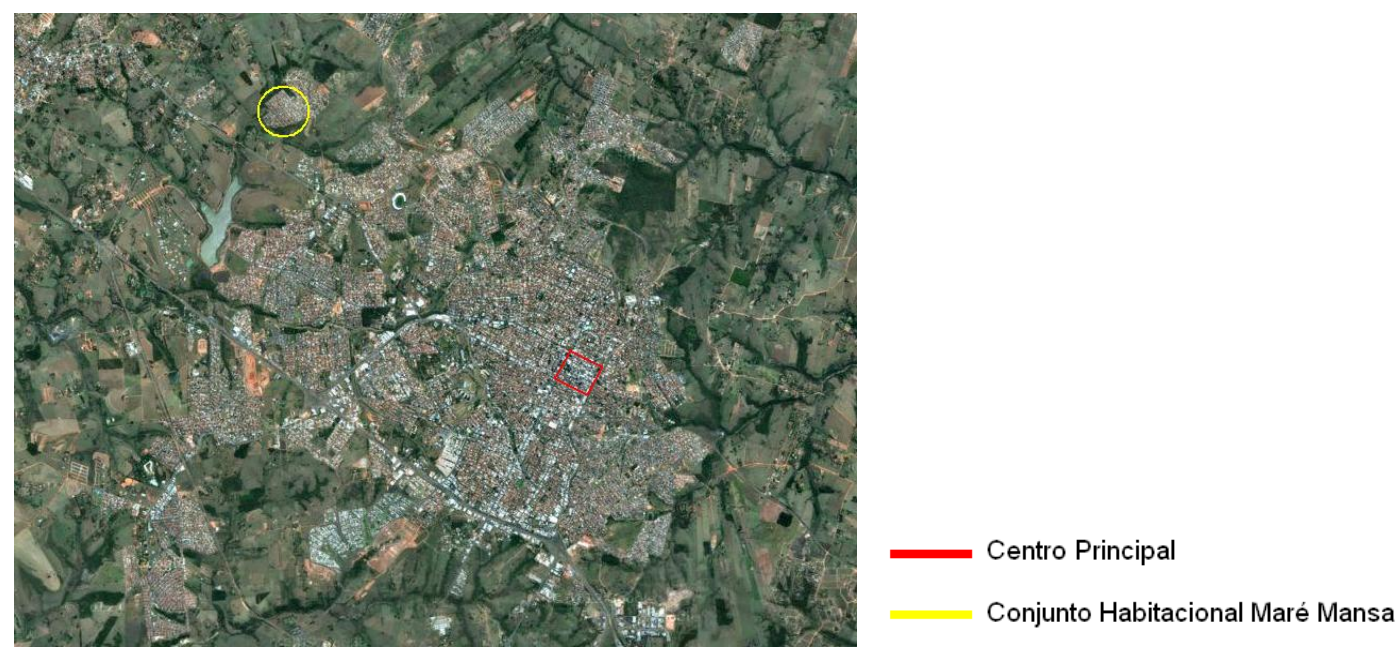

Figura 1. Localização do conjunto habitacional Maré Mansa

Fonte: Google maps, organização - Mayara Albano 
O projeto apresentado à prefeitura municipal de Presidente Prudente apresentava a locação de algumas minas existentes na área, porém omitia a existência de nove, que foram constatadas pela perícia. Em virtude dessa discordância do projeto de implantação e as reais condições da área o projeto foi alterado por determinação do Ministério Público que determinou um a redefinição da área de Preservação Permanente que deveria circundar os córregos adjacentes e assim ocorreu a diminuição na quantidade de unidades habitacionais.

Inúmeras irregularidades na implantação e construção das unidades provocaram problemas no meio ambiente natural, tais como a devastação da mata ciliar dos córregos da Bomba e da Malandra, que teve uma recomposição bastante tumultuada; inúmeros casos de erosão provocadas e agravadas pela inobservância das técnicas construtivas para o tipo de solo do local, indicadas pelo Instituto de Pesquisa e Tecnologia (IPT); projetos de infraestrutura urbana inadequados ao sítio de implantação e que prejudicaram os referidos córregos; atrasos na pavimentação das ruas que provocaram erosões nas ruas com as unidades habitacionais já implantadas, conforme observa-se na Figura 2, entre outros.

Esses problemas observados acarretaram inúmeros danos ao meio ambiente e à qualidade de vida da população. Os córregos adjacentes ao conjunto habitacional sofreram com assoreamento (Figura 3), poluição com os resíduos da construção das unidades e lixos jogados pelos moradores, e ainda hoje persistem, conforme pode ser observado na Figura 4, há animais pastoreando na APP.

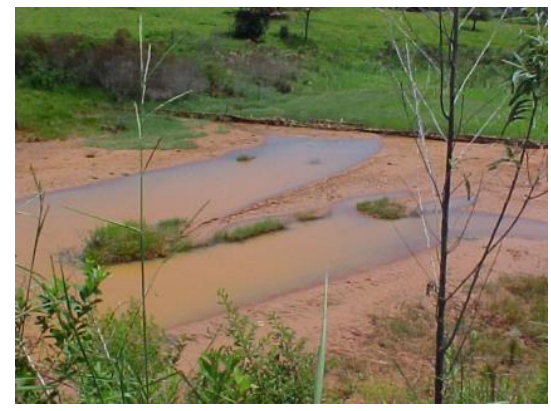

Figura 2. Córrego da Malandra. Fonte: BOIN, 2002.

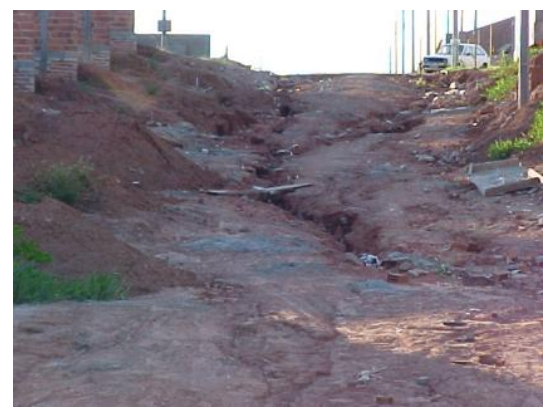

Figura 3. Erosão em uma das ruas do conjunto habitacional. Fonte: BOIN, 2002.

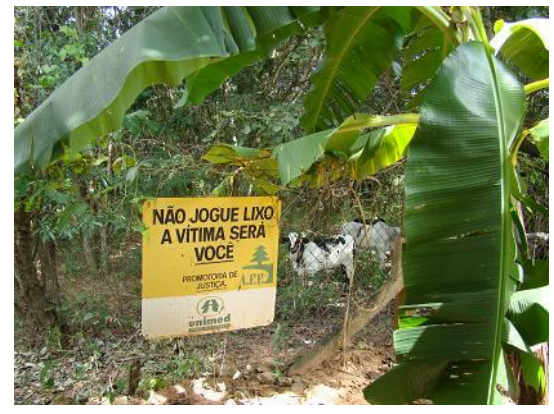

Figura 4. Animais pastoreando em APP.

Fonte: Mayara Albano, 2013.

\section{CONSIDERAÇÕES FINAIS}

Embora o Ministério Público tenha se posicionado no momento da execução desse empreendimento imobiliário, e tomado inúmeras providências para mitigar as repercussões ambientais a fim de promover uma melhor qualidade de vida à população, através do termo de 
ajustamento de conduta firmado, das visitas e relatórios elaborados pela perícia, onde inúmeras providências tiveram que ser tomadas pela construtora, o problema ambiental e a segregação socioespacial constitui um fato. Ainda hoje, encontra-se problemas de desrespeito à Área de Preservação Permanente que resguarda os Córregos da Bomba e da Malandra, onde, quatorze anos após o início das obras de implantação, vê-se animais pastoreando em APP, lixos e entulhos jogados nesta área, impactando o meio ambiente.

Assim, pode-se concluir a importância de um Planejamento Urbano Ambiental, que deveria antever situações como a estudada neste trabalho e, evitar a implantação de bairros que tivessem tantas ressalvas ligadas à questões de tamanha importância para a sociedade, como as habitacionais e ambientais.

\section{REFERÊNCIAS}

ALMEIDA et al. Planejamento Ambiental: caminho para a participação popular e gestão ambiental para o nosso futuro comum - uma necessidade, um desafio. 2a. edição. Rio de Janeiro: Thex Ed, 1999.

ARRUDA, Ângelo M. O arquiteto e o planejamento ambiental e os riscos da falta de discussão. Portal Vitruvius / Romano Guerra Editora Ltda, São Paulo, Arquitextos 015 - texto especial 092, agosto de 2001. Disponível em:<http://www.vitruvius.com.br/arquitextos/arq000/esp092.asp>. Acesso em: 25 de novembro de 2006.

BOIN, Marcos Norberto. Relatório n.1. Procuradoria Geral de Justiça. (1999). . Relatório n. 55. Procuradoria Geral de Justiça. (2002).

CANEPA, C. Cidades Sustentáveis: o município como lócus da sustentabilidade. São Paulo: RCS Editora, 2007.

DIAS, D.S. Desenvolvimento Urbano: princípios constitucionais. Curitiba: Juruá, 2005.

DI SARNO, D.C.L. Elementos de Direito Urbanístico. Barueri: Manole, 2004.

FERRARI, C. Curso de planejamento municipal integrado: urbanismo. 7ạ.edição. São Paulo: Pioneira, 1991.

HONDA, Sibila C.A.L. A centralidade urbana em Presidente Prudente. São Paulo: FAU/UPM, 2000. Dissertação (Mestrado).

HONDA, Sibila C.A.L. Habitação de Baixa Renda como Produto do Capital - o Programa de Arrendamento Residencial (PAR) em Presidente Prudente. São Paulo: FAU/UPM, 2011. Tese (Doutorado). 
MACHADO, L. M. C. P. Qualidade Ambiental: indicadores quantitativos e perceptivos. In: MARTOS, H. L. e MAIA, N. B. Indicadores Ambientais. Sorocaba: Bandeirante Ind. Gráfica S.A, 1997.

MARIA, Yeda Ruiz. Politica Municipal, Desenvolvimento e Gestão Municipais - a zona rural de Anhumas/SP. Presidente Prudente/SP, 2012 (monografia de especialização).

MARICATO, Ermínia. Brasil cidades: alternativas para a crise urbana. Petrópolis, RJ: Vozes, 2001.

PHILIPPI Jr, A.; ROMÉRO, M.A.; BRUNA, G.C. Uma Introdução à Questão Ambiental. In: PHILIPPI Jr, A.; ROMÉRO, M.A.; BRUNA, G.C. (org.). Curso de Gestão Ambiental. Barueri: Manole, 2004. p.3-16.

SILVA, Geovany Jessé Alexandre da; WERLE, Hugo José Scheuer. Planejamento urbano e ambiental nas municipalidades: da cidade a sustentabilidade, da lei a realidade .PAISAGENS EM DEBATE Revista Eletrônica da área Paisagem e Ambiente, FAU.USP - n. 05, dezembro 2007. 